\title{
Empathy and its associations with sociodemographic and personality characteristics in a large UK population sample
}

\section{Authors}

Andrew Sommerlad ${ }^{a, b}$, Jonathan Huntley ${ }^{a, b}$, Gill Livingston ${ }^{a, b}$, Katherine P Rankin ${ }^{c}$, Daisy Fancourt ${ }^{d}$

a Division of Psychiatry, University College London, UK

${ }^{\mathrm{b}}$ Camden and Islington NHS Foundation Trust, London, UK

${ }^{\mathrm{c}}$ Memory and Aging Center, Department of Neurology, University of California, San Francisco, CA, USA.

${ }^{d}$ Department of Behavioural Science and Health, University College London, UK

\section{Corresponding author}

Dr Andrew Sommerlad. Division of Psychiatry, University College London, $6^{\text {th }}$ Floor, Maple House, 149 Tottenham Court Road, London, W1T 7NF, UK

Tel: +44 (0)2076799248

Email: $\underline{\text { a.sommerlad@ucl.ac.uk }}$ 


\section{Abstract}

\section{Background}

Empathy is fundamental to social cognition, driving prosocial behaviour and mental health. Self-reported empathy varies across cultures and there are differing reports of associations with demographic characteristics. We therefore aimed in a UK survey to characterise two main self-reported components of empathy, namely empathic concern (feeling compassion) and perspective taking (understanding others' perspective). We hypothesised that empathy would be associated with age, gender, ethnicity, relationship status, employment, socio-economic status, education, and personality.

\section{Methods}

We asked participants in the COVID-19 Social Study - an internet-based survey of UK-dwelling adults aged $\geq 18$ years - to complete the Interpersonal Reactivity Index subscales measuring empathic concern and perspective taking, and sociodemographic and personality questionnaires. We weighted the sample to be UK population representative and employed multivariable weighted linear regression models.

\section{Results}

In 30,033 respondents, mean empathic concern score was 3.86 (95\% confidence interval $3.85,3.88$ ) and perspective taking was 3.57 (3.56. 3.59), the correlation between these subscores was $0.45(p<0.001)$. In adjusted models, greater empathic concern was associated with female gender, non-white ethnicity, having more education, working in health, social-care, or childcare professions, and having higher neuroticism, extroversion, openness to experience and agreeableness traits. Perspective taking was associated with younger age, female gender, more education, employment in health or social-care, neuroticism, openness, and agreeableness.

\section{Conclusions}

Women and people working in caring professions have higher empathy levels. Perspective taking declines with age but empathic concern does not. Empathic compassion and understanding are distinct dimensions of empathy with differential associations with demographic factors. 


\section{Introduction}

Empathy comprises the ability to feel compassion for another person's experience (emotional empathy) and the cognitive capacity to take the mental perspective of another person in order to understand their feelings (cognitive empathy) (Beadle \& De la Vega, 2019). As a key component of social cognition (Sollberger, Rankin, \& Miller, 2010), empathy is fundamental to guiding prosocial behaviour (Rumble, Van Lange, \& Parks, 2010). Understanding empathy is important as higher levels of empathy are associated with higher life satisfaction (Davis \& Oathout, 1987), and lower rates of loneliness (Beadle, Keady, Brown, Tranel, \& Paradiso, 2012) and depression (Tully, Ames, Garcia, \& Donohue, 2016), especially in carers and healthcare professionals. Emotional and cognitive empathy, measured by self-report using the Interpersonal Reactivity Index (Davis, 1980) domains of empathic concern (akin to emotional empathy) and perspective taking (cognitive empathy), are moderately correlated (Davis, 1980; Song \& Shi, 2017) but appear to be distinct dimensions of empathy with potentially different drivers and consequences (Konrath, 2013). Identifying the links between empathy and static characteristics such as gender and ethnicity or dynamic factors such as aging, education, employment, or social behaviours including marriage and social contact, has the potential to improve our understanding of what affects empathy in different people, and how it changes during the life-course.

A large nationally representative cross-sectional study of US adults, aged 18-90 years old, born between 1920 and 1999, found an inverse-U shaped association of empathy with age, so that both emotional and cognitive empathy increased from young adulthood and peaked in middle-age - around age 60 - before declining (O’Brien, Konrath, Grühn, \& Hagen, 2013). However, we do not know whether the association with age is a cohort effect, meaning that it is unclear whether individuals decline in empathy, possibly related to other symptoms of cognitive decline, or whether age differences are related to varying life experiences and education levels in different age cohorts. If the reduction is because of cognitive decline then cognitive empathy might be expected to be more strongly associated with age than empathic concern, as cognitive empathy is more impaired than empathic concern in patients with neurodegenerative disease (Dermody et al., 2016), and the association will be there in cohorts from differing cultures.

Additionally, women score higher on empathy scales than men (Christov-Moore et al., 2014; Davis, 1983; O'Brien et al., 2013) and several personality traits, including conscientiousness, openness to experience, and agreeableness are linked to higher empathy (Chopik, O’Brien, \& Konrath, 2017; Guilera, Batalla, Forné, \& Soler-González, 2019; Song \& Shi, 2017). However, studies of personality and empathy have usually been carried out in specific groups such as students or adolescents and the relationship may differ in other groups (Guilera et al., 2019; Song \& Shi, 2017). Empathy would be expected to be related to career choice with those choosing the caring professions having higher emotional empathy, and higher levels of cognitive 
empathy are associated with better mental health outcomes for informal family carers (Jütten, Mark, \& Sitskoorn, 2019) and healthcare professionals (Cho \& Jeon, 2019), suggesting that cognitive empathy may mediate stressful aspects of providing care to another person perhaps by allowing understanding of the feelings of the person cared for. However, empathy varies in different countries and cultures (Chopik et al., 2017) so examination of empathy and its associations in specific settings is important. Furthermore, considering a range of different characteristics may elucidate the nature of the relationships of these factors with empathy. For example, factors which can be considered constant in individuals, such as ethnicity, gender or personality cannot be consequences but may be causes of empathy, whereas fluid characteristics like employment, socioeconomic status or choosing a partner may be the product, or also potentially cause, of empathy.

Therefore, in this study, we aim to describe levels of self-reported empathic concern and perspective taking for the first time in a large UK population, and according to a range of sociodemographic characteristics. We describe cross-sectional associations of empathic concern and perspective taking with age, gender, ethnicity, relationship status, education, occupation, caring responsibilities and personality. Our specific objectives are to test the following research hypotheses:

1. Self-reported empathy will be positively associated with female gender, socio-economic and relationship status, education, and personality traits.

2. Older age will be more strongly negatively associated with perspective taking than empathic concern

3. Empathic concern but not perspective taking will be associated with being a carer and working in caring professions

\section{Methods}

\section{Study design and participants}

This study is a cross-sectional analysis of data from the COVID-19 Social Study (Fancourt, Steptoe, \& Bu, 2020), a longitudinal cohort study of UK-dwelling participants aged 18 years and older. The COVID-19 Social Study started on $21^{\text {st }}$ March 2020 to consider social and mental effects of the COVID-19 pandemic in the UK at the time of strict social distancing legislation beginning. Its large, well-stratified and well-phenotyped sample make it a suitable dataset for exploring broader psychological and social factors beyond the pandemic itself.

The study was promoted via a range of routes: through large databases of adults who had consented to be contacted about health research; United Kingdom Research Institute (UKRI) mental health research networks; print, social media and digital media coverage; targeted recruitment to people from low income, low educational, and unemployed backgrounds through advertising and recruitment, and to vulnerable 
groups via mental health research networks. Respondents were not paid to participate. Full details of the study protocol are available at www.covidsocialstudy.org.

Eligibility criteria for participants in this analysis were 1 ) being aged $\geq 18$ years, 2 ) joining the COVID-19 study any time between study inception on $21^{\text {st }}$ March 2020 and $20^{\text {th }}$ June 2020, which was the last date of inclusion of the questions about empathy, 3) completing a baseline questionnaire on joining the study and completing the empathy questionnaire between $13^{\text {th }}$ and $20^{\text {th }}$ June (week 13 of the study), 4) residing in the UK at the time of baseline questionnaire completion.

The study was approved by the UCL Research Ethics Committee [12467/005] and all participants gave informed consent.

\section{Measures}

\section{Empathic concern and perspective taking}

We measured empathic concern (EC) and perspective taking (PT) domains using questions from the Interpersonal reactivity index (IRI) (Davis, 1980), which is a 28 item scale answered on a 5-point Likert scale ranging from "Does not describe me well" to "Describes me very well". It has four subscales measuring different dimensions of empathy and is validated in general populations. We used the 14 questions (figure 1) which assess empathic concern and perspective taking. Scores for the two subscales were averaged across each domain giving mean scores for empathic concern and perspective taking ranging from 1-5. Higher scores denote higher empathy.

Factor analysis in 1161 US college students indicated that the IRI subscales measuring empathic concern and perspective taking have low-moderate correlation ( $r=0.33$ ) (Davis, 1980). The scales have high internal reliability and test-retest reliability (Konrath, 2013) and internal consistency for the empathic concern and perspective taking subscales, measured by Cronbach's alpha, are 0.72 and 0.77 respectively (Hemmerdinger, Stoddart, \& Lilford, 2007). The PT subscale correlates, as expected, with measures of cognitive empathy, and EC correlates with emotional empathy measures (Davis, 1983). The IRI is considered to be a measure of 'trait-based' empathy, meaning the individual's long-term, rather than situational, tendency to empathise with others, thus it is less likely to reflect specifically state-level empathic feelings during the COVID-19 pandemic.

\section{Covariates}

We chose to include information on sociodemographic, lifestyle and personality factors based on our a priori hypotheses and previous literature. The following covariates were derived from the baseline questionnaire: age (in categories 18-24, 25-34, 35-44, 45-54, 55-64, 65-74, $\geq 75$ years; gender (male, female, other/prefer not to say); ethnicity (White, Other ethnicities); relationship status (never married, divorced/widowed, in a 
relationship but not cohabiting, co-habiting with partner or spouse); and living status (living alone or live with others). Previous (pre-COVID) social contact frequency was assessed by asking 'how often do you usually meet up with people face-to-face socially, not for work (e.g. friends, family, relatives, social events with colleagues)' (less than weekly, 1-2 times per week, 3 or more times weekly).

We also derived information about employment (At school or university or in employment, or not working); household income $(<£ 30,000, \geq € 30,000)$; education status (Lower secondary or below, higher secondary, or graduate); whether they had caring responsibilities for relatives or friends, people with long-term conditions, or grandchildren $(\mathrm{Y} / \mathrm{N})$; and whether employed as a 'keyworker' as defined by the UK government (health or social care worker, teacher or childcare worker, other keyworker role e.g. public service worker, utility worker, transport worker, none). Participants were also asked whether they had any pre-existing long-term physical illness (hypertension, diabetes, heart disease, lung disease, cancer, another chronic condition) or whether they were pregnant.

Personality was measured using the Big Five Inventory (BFI-2), which measures five domains consisting of 15 facets: extraversion (sociability, assertiveness, and energy level), agreeableness (compassion, respectfulness, and trust), conscientiousness (organisation, productiveness, and responsibility), nervousness (anxiety, depression, and emotional volatility), and openness (intellectual curiosity, aesthetic sensitivity, and creative imagination) (Soto \& John, 2017). Respondents rate their agreement with each statement using a 7-point scale ranging from "strongly disagree" to "strongly agree", and we created scores ranging from 3-21 by summing together the three questions for each personality domain.

\section{Analyses}

We first described the demographics of the sample, and physical health and personality traits. We then examined empathic concern and perspective taking and reported these according to age and gender. We examined perspective taking and empathic concern in separate models as the domains have low-moderate correlation. We present unweighted results as well as results weighted to the proportions of age group, gender and educational level on the basis of Office for National Statistics (ONS) population estimates and Annual Population Survey (Office for National Statistics, 2020), to account for the non-random nature of the sample.

\section{Association of empathy with sociodemographic characteristics}

We assessed associations of empathic concern and perspective taking with age, gender, ethnicity, education level, living situation, marital status, employment, household income, keyworker status, carer status, usual face-to-face contact, physical health, and 'big-five' personality characteristics. We first used univariable linear regression to assess unadjusted associations and then included all variables in a multivariable linear regression model. 


\section{Sensitivity analyses}

We repeated the above analyses without weighting. In additional analyses, as $11 \%$ of the cohort had missing data on at least one predictor, we also conducted sensitivity analyses using multiple imputation by chained equations (White, Royston, \& Wood, 2011) for missing covariates to maximise statistical power. We used the mi package in STATA to create ten imputed datasets constructed from all potential covariate and outcome variables, before using linear regression on each imputed dataset with weighting as above, and used Rubin's rules to combine coefficients.

All analyses were conducted using STATA SE version 14.2 (Statacorp).

\section{Results}

Analyses included 30,033 people and full characteristics of the sample are in table 1 . Three-quarters $(22,461)$ of participants were women and the mean age was 54.4 (standard deviation (SD) 14.1) years. Respondents were predominantly from white ethnic groups $(28,794,96.1 \%)$ and 20,822 (69.3\%) had attained a degree or higher education level. The majority $(17,323,57.7 \%)$ were in employment and 16,093 (59.5\%) reported a household income of $£ 30,000$ or greater. Two thirds $(19,272,64.2 \%)$ were cohabiting with a partner or spouse and 6,494 (21.6\%) lived alone. One-fifth $(6,140)$ of respondents reported working in a 'keyworker' role, including $2,807(9.4 \%)$ who worked in health or social care.

Mean empathic concern score was 3.97 (standard deviation 0.66, range 1 - low to 5 - high) and mean perspective taking score was $3.67(0.69,1-5) ; 20 \%$ of the variance between these domains was shared $(r=0.45, p<0.001)$. Mean scores weighted by gender, age, ethnicity, education, and country of residence within the UK were 3.86 for empathic concern $(95 \%$ confidence interval $3.85,3.88)$ and 3.57 for perspective taking $(3.56,3.59)$.

Mean scores for women were 4.06 for empathic concern $(0.63,1-5)$ and 3.74 for perspective taking $(0.68$, 1$5)$ and for men 3.70 for empathic concern $(0.66,1-5)$ and 3.48 for perspective taking $(0.69,1-5)$. Empathy scores varied for men and women by age. For women, there was an inverse-u association for both empathic concern and perspective taking. For men, empathic concern increased and perspective taking decreased with older age (figure 1; Quadratic line of best fit due to non-linear associations $(p<0.001)$ ). Empathy scores according to all characteristics are in Appendix 1.

\section{Association of sociodemographic characteristics with empathic concern}

Complete data were obtained from 25,169 (83.8\%) of participants, on whom we performed our primary complete case analyses. In univariable weighted models, younger age, female gender, higher education, divorced or widowed marital status, being a health, social care, or childcare worker or teacher, being a carer, 
having more face-to-face social contact, and higher levels of neuroticism, extroversion, openness, agreeableness and conscientiousness were associated with higher levels of empathic concern (table 2).

In multivariable models, weighted for UK population distribution, mean empathic concern score was 0.23 $(0.21,0.26)$ points higher for women than men, $0.08(0.02,0.14)$ points higher for non-white respondents than white respondents, $0.04(0.00,0.07)$ points higher for those with graduate v lower secondary education, $0.11(0.06,0.15)$ points higher for health or social care workers and $0.06(0.00,0.11)$ higher for teachers or childcare workers compared to those not in these or other 'keyworker' roles. Each standard deviation higher score on neuroticism was associated with 0.11 higher empathic concern score $(0.10,0.12)$. For one standard deviation higher extroversion score, empathic concern was 0.06 points higher $(0.05,0.07)$. Each standard deviation higher openness to experience was associated with 0.11 higher empathic concern $(0.10,0.13)$ and for each standard deviation of agreeableness, empathic concern was 0.24 points higher $(0.23,0.25)$ (Table 2$)$.

Results were consistent in analyses without population weighting (appendix 2), and in models based on the full sample of 30,033 respondents with multiple imputation for missing data (appendix 3).

\section{Association of sociodemographic characteristics with perspective taking}

In univariable models, higher levels of perspective taking were associated with younger age, female gender, higher education, marital status (being widowed or divorced), being in employment, receiving high household income, being a health, social care, or childcare worker or teacher, being a carer, having more face-to-face social contact, having a long-term physical health condition, and higher levels of neuroticism, extroversion, openness, agreeableness, and conscientiousness (Table 3).

In weighted multivariable models, mean perspective taking score was associated with younger age (0.23 $(0.34,0.13)$ points higher for $18-25$ year olds compared to respondents aged 75 years or older). Mean score was $0.18(0.16,0.21)$ points higher for women and higher for those with more education $(0.09(0.06,0.12)$ points higher for graduate $v$ those with lower secondary education). Being a health or social care worker was associated with $0.05(0.01,0.10)$ higher score. Each standard deviation lower of neuroticism, and higher of openness to experience and agreeableness were associated with $0.08(0.06,0.08), 0.09(0.08,0.11)$, and 0.26 $(0.24,0.27)$ higher perspective taking scores respectively (Table 3 ).

Results were similar in analyses without weighting for population norms (appendix 4), and in models in which we imputed missing data on the full sample of 30,033 respondents (appendix 3 ). 


\section{Discussion}

This study is the first to describe self-reported empathic concern and perspective taking in a large UK sample. We found variations in empathy according to age and these associations also differed between women and men. There was an inverse- $u$ association for empathic concern and perspective taking for women, with both improving with age and then beginning to fall from around age 45 . Women's scores did not fall to the level of men's, even in older age up to the age of 90 years, when men's empathic concern increased, as their perspective taking decreased. In multivariable models, perspective taking, but not empathic concern, was independently associated with age, and both domains were higher in women than men and in those with more education. Those with health and social care jobs scored higher in empathic concern and perspective taking, and teachers and childcare workers had higher empathic concern scores, as did non-white people. Higher neuroticism was associated with more empathic concern and less perspective taking, extroversion was associated with higher empathic concern, and openness to experience and agreeableness were associated with higher scores on both subscales.

The mean scores in this study are similar to those in the initial 1980 validation paper which examined empathy using the interpersonal reactivity index in US college students (Davis, 1980). It found mean empathic concern in women 4.10 and men 3.72 , compared to 4.06 and 3.70 respectively in our sample, and perspective taking to be 3.57 in women and 3.40 in men, compared to 3.74 and 3.48 in our study. Other studies have also found consistent scores on IRI, such as nationally representative US study with mean age 39 years conducted in 2010 which found mean empathic concern 3.77 and perspective taking 3.66 to compare to our study's scores weighted to the UK population which were 3.86 and 3.57 .

However, there is variation in self-reported empathy in different countries, for example the lowest scores of 3.15 and 3.16 on EC and PT respectively were in Lithuania, and the highest scores in Ecuador (4.12 and 3.82), meaning that comparison to different countries may be invalid. UK data from an international study had mean empathic concern 3.49 and perspective taking 3.44 in 2,754 people aged 37 years on average (Chopik et al., 2017), which was lower than in our study; and another UK study of first year medical students found women to have mean EC and PT 4.01 and 3.77 and men 3.78 and 3.57, which was more similar to our results (Quince, Parker, Wood, \& Benson, 2011). Our study is based on a larger sample, with better coverage of age and social groups and is the best stratified assessment of empathy to date, so should provide the most accurate normative figures.

Women's higher empathy ratings compared to men found in this study are consistently shown in observational studies which use either self-rating scales, implicit measurements, or task-based assessment of empathy (Christov-Moore et al., 2014). Our study adds that this persists independently of potential confounding effects of personality factors and social contact frequency. Potential explanations of higher 
empathy for women than men are culturally-driven differences in socialisation behaviour by gender (Strayer \& Roberts, 2004), or biological mechanisms, such as hormone-induced alterations in brain development such as through lower testosterone levels (Van Honk et al., 2011) or differential response to oxytocin (Domes, Heinrichs, Michel, Berger, \& Herpertz, 2007), with genetic selection favouring more empathic women. Response bias has also been suggested as an explanation for gender differences in self-reported empathy, supported by discrepancies in self-reported and task-based assessment of empathy where women overreported their own empathy (Baez et al., 2017).

We expected that perspective taking would reduce with greater age, but that empathic concern may not, due to the cognitive requirements of taking another person's perspective. Our results were overall supportive of this hypothesis, with higher perspective taking associated with younger age in multivariable analyses, but no association between empathic concern and age in these adjusted models. There is evidence of age-related deficits in the cognitive ability to accurately perceive another person's emotions (Richter \& Kunzmann, 2011) and deficits in empathy are associated with structural abnormalities in the dorsal medial prefrontal cortex (Moran, Jolly, \& Mitchell, 2012) and insula (Moore, Dev, Jeste, Dziobek, \& Eyler, 2015) as well as right temporoparietal deficits in healthy older people and those with neurodegenerative diseases (Rankin et al., 2006). This suggests that decline in the cognitive ability to empathise with others may be linked with age-related changes in neural substrate, although other possibilities related to cultural and environmental changes in cognitive empathy are also possible.

The inverse relationship between age and perspective taking or cognitive empathy has been found in several previous studies (Bailey, Henry, \& Von Hippel, 2008; Beadle, Paradiso, et al., 2012; Beadle, Sheehan, Dahlben, \& Gutchess, 2015) and the lack of association of emotional empathy with age also replicates some previous findings (Beadle, Paradiso, et al., 2012; Beadle et al., 2015). Our study builds on the existing evidence as our stratified description of these subscales by gender indicated that the differences in the association of these two domains with age may have been driven by the higher self-reported empathic concern in older men. Future studies should consider in greater detail what drives the effect of gender on empathy's association with age.

The strongest associations with empathy found in our study were for personality traits, in particular, agreeableness and openness to experience which had strong positive associations with both empathy subscales, and neuroticism which had a positive independent association with empathic concern and a negative association with perspective taking. Previous studies have found personality traits to account for around $20 \%$ of the variance of these domains (Song \& Shi, 2017), although studies have often been of students who may differ from a more general population (Melchers et al., 2016). One international study examined correlations between the big five personality characteristics and found similar inverse correlation 
between neuroticism and perspective taking, and, in age and sex-adjusted models, that empathic concern was most closely associated with agreeableness in 896 participants with mean age 21 years in China, Denmark, Germany and the United States (Melchers et al., 2016). Our study adds that these associations are independent of other potentially important confounders such as education, and seen throughout the lifespan. The strong association between personality and empathy may be partly due to response bias for both of these self-reported domains whereby individuals may have bias towards uniformly reporting that all of their personality and empathy traits are high, leading to inflation of the association.

Our findings of increased perspective taking and empathic concern in healthcare workers is consistent with our hypothesis. Some previous research suggests that empathy improves during healthcare training (Cunico, Sartori, Marognolli, \& Meneghini, 2012). However other studies have suggested that empathy is stable during training (Quince et al., 2011), and having a higher level of empathy may mean that a person is more likely to choose such roles. Associations between professional caring roles (such as health/social-care work and childcare/teaching) and empathy were stronger for empathic concern than for perspective taking. For perspective taking, no association was found for teachers, or for informal caring (e.g. for a friend, relative or grandchild),. Higher levels of empathy in healthcare professionals have been associated with lower rates of burnout (Wilkinson, Whittington, Perry, \& Eames, 2017) suggesting that these social cognitive domains are critical buffers to the potentially detrimental effects of the stress of a caring role.

We found that more education was associated with both empathy domains, more strongly with perspective taking than empathic concern, and that the association persisted after adjustment for income. Having more education may increase cognitive ability to consider others' perspective and provide skills which encourage thoughts about others (Schieman \& Van Gundy, 2000). Empathic concern, but not perspective taking, was higher in non-White respondents, possibly reflecting the cultural differences in empathy demonstrated in large international studies (Chopik et al., 2017; Melchers et al., 2016), but the small number of non-White participants meant that we could not examine this in more detail considering different ethnic groups. The other socio-demographic factors we examined were not independently associated with empathy, including living alone, marital status, and social contact with others, being in employment or having high income, and having long-term health conditions. These factors are largely fluid and can vary throughout adulthood, unlike gender, education and personality, and their lack of association suggests that empathy may be largely determined by gender, personality and education, with subsequent changes over time related to aging.

\section{Strengths and limitations}

This study has strengths including its large sample size and its extensive measurement of sociodemographic and lifestyle factors. However, there are several limitations. The study is not nationally representative, although it does have good stratification across all major socio-demographic groups and analyses were 
weighted for population estimates of core demographics. Whilst the recruitment strategy deliberately oversampled from disadvantaged groups, more extreme experiences may not be adequately captured. Empathy was measured in the $13^{\text {th }}$ week of the study, where participants would have joined any time between week 1 and 13, meaning that empathy may have been measured between 0 and 3 months apart from covariate measurement. However, as empathy is thought to be stable over time, this should not have affected analyses. This study was conducted during the first wave of COVID-19 pandemic, during 'lockdown' in the UK at a time of significant stress. However, the Interpersonal Reactivity Index is conceptually designed to measure long-term empathic traits, rather than empathy in specific personal or wider social situations, with good to excellent test-retest reliability (Davis, 1980), so the potential difference in data collection timings, and the setting during COVID is unlikely to affect the associations we found.

Our study is a cross-sectional analysis of baseline data making it difficult to be certain of the mechanism and direction of the associations we found and we focused on sociodemographic associations, rather than the impact of empathy on mental health. Finally, our first-person assessment of empathy potentially limits our conclusions as we did not assess empathy with an experimental or task-based method (Murphy \& Lilienfeld, 2019). The self-report nature of the IRI makes it susceptible to social desirability bias (Watson \& Morris, 1991) though observer ratings correlate moderately with self-report (Saroglou, Pichon, Trompette, Verschueren, \& Dernelle, 2005) and links between empathy self-report and social behaviour support the scale's validity (Chopik et al., 2017; Davis, 1983).

\section{Implications}

This is the first large-scale study of empathy in a UK population, providing normative data, and we report similar levels of self-reported empathic concern and perspective taking in this population to international comparators. We describe the associations of empathy with a range of key demographic, lifestyle and personality characteristics, suggesting that empathy may be biologically and culturally determined by gender, education and personality early in life, but unaffected by other social factors determined later in life, with the exception of vocation, where empathy may guide choice of career. We found that perspective taking declines with greater age but that empathic concern does not, partly driven by higher levels of empathic concern in older men.

Future research should seek to understand whether the decline in perspective taking is general or in those who will go on to develop cognitive impairment, and which biological and psycho-social mechanisms drive gender differences in age-related empathy changes. Self-reported empathy is higher in people working in caring professions independent of personality and educational level and, considering the key importance of this domain in guiding social behaviour and protecting against adverse mental health outcomes, future studies should determine the extent to which this can be modified or is an inherent trait which should be 
sought for these roles. As empathy is a crucial building block of social interactions, understanding more about greater empathy is crucially important to societal function. 


\section{Acknowledgements}

The researchers are grateful for the support of a number of organisations with their recruitment efforts including: the UKRI Mental Health Networks, Find Out Now, UCL BioResource, SEO Works, FieldworkHub, and Optimal Workshop. The study was also supported by HealthWise Wales, the Health and Care Research Wales initiative, which is led by Cardiff University in collaboration with SAIL, Swansea University.

\section{Financial support}

This Covid-19 Social Study was funded by the Nuffield Foundation [WEL/FR-000022583], but the views expressed are those of the authors and not necessarily the Foundation. The study was also supported by the MARCH Mental Health Network funded by the Cross-Disciplinary Mental Health Network Plus initiative supported by UK Research and Innovation [ES/S002588/1], and by the Wellcome Trust [221400/Z/20/Z].

AS is funded by the UCL / Wellcome Trust Institutional Strategic Support Fund (204841/Z/16/Z) and by the University College London Hospitals' (UCLH) National Institute for Health Research (NIHR) Biomedical Research Centre (BRC).

JH is funded by a Wellcome Trust Clinical Research Career Development Fellowship (214547/Z/18/Z) and supported by UCLH NIHR BRC.

GL is supported by UCLH NIHR BRC and North Thames NIHR ARC (Applied Research Collaboration) and as a NIHR Senior Investigator.

KPR receives research support from the National Institutes for Health

DF is funded by the Wellcome Trust [205407/Z/16/Z].

\section{Conflicts of interests}

All authors declare no conflicts of interest.

\section{Ethical standards}

The authors assert that all procedures contributing to this work comply with the ethical standards of the relevant national and institutional committees on human experimentation and with the Helsinki Declaration of 1975, as revised in 2008. The study was approved by the UCL Research Ethics Committee [12467/005] and all participants gave informed consent. 


\section{References}

Baez, S., Flichtentrei, D., Prats, M., Mastandueno, R., García, A. M., Cetkovich, M., \& Ibáñez, A. (2017). Men, women... who cares? A population-based study on sex differences and gender roles in empathy and moral cognition. PloS one, 12(6), e0179336.

Bailey, P. E., Henry, J. D., \& Von Hippel, W. (2008). Empathy and social functioning in late adulthood. Aging and Mental Health, 12(4), 499-503.

Beadle, J. N., \& De la Vega, C. E. (2019). Impact of aging on empathy: Review of psychological and neural mechanisms. Frontiers in psychiatry, 10, 331.

Beadle, J. N., Keady, B., Brown, V., Tranel, D., \& Paradiso, S. (2012). Trait empathy as a predictor of individual differences in perceived loneliness. Psychological reports, 110(1), 3-15.

Beadle, J. N., Paradiso, S., Kovach, C., Polgreen, L., Denburg, N., \& Tranel, D. (2012). Effects of age-related differences in empathy on social economic decision-making. International psychogeriatrics/IPA, 24(5), 822.

Beadle, J. N., Sheehan, A. H., Dahlben, B., \& Gutchess, A. H. (2015). Aging, empathy, and prosociality. Journals of Gerontology Series B: Psychological Sciences and Social Sciences, 70(2), 213-222.

Cho, E., \& Jeon, S. (2019). The role of empathy and psychological need satisfaction in pharmacy students' burnout and well-being. BMC medical education, 19(1), 43.

Chopik, W. J., O'Brien, E., \& Konrath, S. H. (2017). Differences in empathic concern and perspective taking across 63 countries. Journal of Cross-Cultural Psychology, 48(1), 23-38.

Christov-Moore, L., Simpson, E. A., Coudé, G., Grigaityte, K., lacoboni, M., \& Ferrari, P. F. (2014). Empathy: gender effects in brain and behavior. Neuroscience \& Biobehavioral Reviews, 46, 604-627.

Cunico, L., Sartori, R., Marognolli, O., \& Meneghini, A. M. (2012). Developing empathy in nursing students: a cohort longitudinal study. Journal of clinical nursing, 21(13-14), 2016-2025.

Davis, M. H. (1980). A multidimensional approach to individual differences in empathy.

Davis, M. H. (1983). Measuring individual differences in empathy: Evidence for a multidimensional approach. Journal of personality and social psychology, 44(1), 113.

Davis, M. H., \& Oathout, H. A. (1987). Maintenance of satisfaction in romantic relationships: Empathy and relational competence. Journal of personality and social psychology, 53(2), 397.

Dermody, N., Wong, S., Ahmed, R., Piguet, O., Hodges, J. R., \& Irish, M. (2016). Uncovering the neural bases of cognitive and affective empathy deficits in Alzheimer's disease and the behavioral-variant of frontotemporal dementia. Journal of Alzheimer's Disease, 53(3), 801-816.

Domes, G., Heinrichs, M., Michel, A., Berger, C., \& Herpertz, S. C. (2007). Oxytocin improves "mind-reading" in humans. Biological psychiatry, 61(6), 731-733.

Fancourt, D., Steptoe, A., \& Bu, F. (2020). Trajectories of depression and anxiety during enforced isolation due to COVID-19: longitudinal analyses of 59,318 adults in the UK with and without diagnosed mental illness. medRxiv.

Guilera, T., Batalla, I., Forné, C., \& Soler-González, J. (2019). Empathy and big five personality model in medical students and its relationship to gender and specialty preference: a cross-sectional study. BMC medical education, 19(1), 57.

Hemmerdinger, J. M., Stoddart, S. D., \& Lilford, R. J. (2007). A systematic review of tests of empathy in medicine. BMC medical education, 7(1), 24.

Jütten, L. H., Mark, R. E., \& Sitskoorn, M. M. (2019). Empathy in informal dementia caregivers and its relationship with depression, anxiety, and burden. International journal of clinical and health psychology, 19(1), 12-21.

Konrath, S. (2013). A critical analysis of the Interpersonal Reactivity Index. MedEdPORTAL Directory and Repository of Educational Assessment Measures (DREAM).

Melchers, M. C., Li, M., Haas, B. W., Reuter, M., Bischoff, L., \& Montag, C. (2016). Similar personality patterns are associated with empathy in four different countries. Frontiers in psychology, 7, 290.

Moore, R. C., Dev, S. I., Jeste, D. V., Dziobek, I., \& Eyler, L. T. (2015). Distinct neural correlates of emotional and cognitive empathy in older adults. Psychiatry Research: Neuroimaging, 232(1), 42-50. 
Moran, J. M., Jolly, E., \& Mitchell, J. P. (2012). Social-cognitive deficits in normal aging. Journal of neuroscience, 32(16), 5553-5561.

Murphy, B. A., \& Lilienfeld, S. O. (2019). Are self-report cognitive empathy ratings valid proxies for cognitive empathy ability? Negligible meta-analytic relations with behavioral task performance. Psychological Assessment, 31(8), 1062.

O'Brien, E., Konrath, S. H., Grühn, D., \& Hagen, A. L. (2013). Empathic concern and perspective taking: Linear and quadratic effects of age across the adult life span. Journals of Gerontology Series B: Psychological Sciences and Social Sciences, 68(2), 168-175.

Office for National Statistics. (2020). Population estimates for the UK, England and Wales, Scotland and Northern Ireland - Office for National Statistics. Retrieved from https://www.ons.gov.uk/peoplepopulationandcommunity/populationandmigration/populationesti mates/bulletins/annualmidyearpopulationestimates/mid2018

Quince, T. A., Parker, R. A., Wood, D. F., \& Benson, J. A. (2011). Stability of empathy among undergraduate medical students: a longitudinal study at one UK medical school. BMC medical education, 11(1), 90.

Rankin, K. P., Gorno-Tempini, M. L., Allison, S. C., Stanley, C. M., Glenn, S., Weiner, M. W., \& Miller, B. L. (2006). Structural anatomy of empathy in neurodegenerative disease. Brain, 129(11), 2945-2956.

Richter, D., \& Kunzmann, U. (2011). Age differences in three facets of empathy: Performance-based evidence. Psychology and aging, 26(1), 60.

Rumble, A. C., Van Lange, P. A., \& Parks, C. D. (2010). The benefits of empathy: When empathy may sustain cooperation in social dilemmas. European Journal of Social Psychology, 40(5), 856-866.

Saroglou, V., Pichon, I., Trompette, L., Verschueren, M., \& Dernelle, R. (2005). Prosocial behavior and religion: New evidence based on projective measures and peer ratings. Journal for the scientific study of religion, 44(3), 323-348.

Schieman, S., \& Van Gundy, K. (2000). The personal and social links between age and self-reported empathy. Social Psychology Quarterly, 152-174.

Sollberger, M., Rankin, K. P., \& Miller, B. L. (2010). Social cognition. Lifelong Learning in Neurology, 16(4), 6985.

Song, Y., \& Shi, M. (2017). Associations between empathy and big five personality traits among Chinese undergraduate medical students. PloS one, 12(2), e0171665.

Soto, C. J., \& John, O. P. (2017). The next Big Five Inventory (BFI-2): Developing and assessing a hierarchical model with 15 facets to enhance bandwidth, fidelity, and predictive power. Journal of personality and social psychology, 113(1), 117.

Strayer, J., \& Roberts, W. (2004). Children's anger, emotional expressiveness, and empathy: Relations with parents' empathy, emotional expressiveness, and parenting practices. Social development, 13(2), 229-254.

Tully, E. C., Ames, A. M., Garcia, S. E., \& Donohue, M. R. (2016). Quadratic associations between empathy and depression as moderated by emotion dysregulation. The Journal of Psychology, 150(1), 15-35.

Van Honk, J., Schutter, D. J., Bos, P. A., Kruijt, A.-W., Lentjes, E. G., \& Baron-Cohen, S. (2011). Testosterone administration impairs cognitive empathy in women depending on second-to-fourth digit ratio. Proceedings of the National Academy of Sciences, 108(8), 3448-3452.

Watson, P., \& Morris, R. J. (1991). Narcissism, empathy and social desirability. Personality Individual differences, 12(6), 575-579.

White, I. R., Royston, P., \& Wood, A. M. (2011). Multiple imputation using chained equations: issues and guidance for practice. Statistics in medicine, 30(4), 377-399.

Wilkinson, H., Whittington, R., Perry, L., \& Eames, C. (2017). Examining the relationship between burnout and empathy in healthcare professionals: A systematic review. Burnout Research, 6, 18-29. 
Empathic concern:

1) I often have tender, concerned feelings for people less fortunate than me.

2) Sometimes I don't feel very sorry for other people when they are having problems. $\left({ }^{*}\right)$

3) When I see someone being taken advantage of, I feel kind of protective towards them.

4) Other people's misfortunes do not usually disturb me a great deal. $\left({ }^{*}\right)$

5) When I see someone being treated unfairly, I sometimes don't feel very much pity for them. $\left({ }^{*}\right)$

6) I would describe myself as a pretty soft-hearted person.

7) I am often quite touched by things that I see happen.

\section{Perspective-taking:}

1) I sometimes find it difficult to see things from the "other guy's" point of view. $\left({ }^{*}\right)$

2) I try to look at everybody's side of a disagreement before I make a decision.

3) I sometimes try to understand my friends better by imagining how things look from their perspective.

4) If I'm sure I'm right about something, I don't waste much time listening to other people's arguments. $(*)$

5) I believe that there are two sides to every question and try to look at them both.

6) When I'm upset at someone, I usually try to "put myself in his shoes" for a while.

7) Before criticizing somebody, I try to imagine how I would feel if I were in their place.

Responses were given on a 5-item Likert scale with two anchors ( $A=$ Does not describe me well; $E=$ Describes me very well). Questions were scored from 1 to 5 and questions marked with $\left({ }^{*}\right)$ were reverse-scored. 


\begin{tabular}{|c|c|c|c|}
\hline Characteristic & Category & $\begin{array}{l}\text { Unweighted } \mathbf{N}(\%) \\
* \text { Mean (sd, range) }\end{array}$ & $\begin{array}{l}\text { Weighted \% } \\
* \text { Mean }(95 \% \mathrm{Cl}) \\
\end{array}$ \\
\hline \multirow[t]{8}{*}{ Age (years) } & Mean (sd, range) & $54.4(14.1,18-90)$ * & $55.0(54.7,55.3) *$ \\
\hline & $18-25$ & $528(1.8)$ & $4.4 \%$ \\
\hline & $25-34$ & $2,612(8.7)$ & $8.6 \%$ \\
\hline & $35-44$ & $4,524(15.1)$ & $12.4 \%$ \\
\hline & $45-54$ & $6,310(21.0)$ & $17.1 \%$ \\
\hline & $55-64$ & $7,819(26.0)$ & $25.2 \%$ \\
\hline & $65-74$ & $6,615(22.0)$ & $25.6 \%$ \\
\hline & $\geq 75$ & $1,625(5.4)$ & $6.7 \%$ \\
\hline \multirow[t]{3}{*}{ Gender } & Female & $22,461(74.8)$ & $50.8 \%$ \\
\hline & Male & $7,455(24.8)$ & $49.2 \%$ \\
\hline & Other / prefer not to say & $117(0.4)$ & \\
\hline \multirow[t]{3}{*}{ Ethnicity } & White & $28,794(96.1)$ & $91.7 \%$ \\
\hline & Other & $1,442(3.9)$ & $8.3 \%$ \\
\hline & Missing & 97 & \\
\hline \multirow[t]{3}{*}{ Educational level } & Lower secondary & $4,139(13.8)$ & $32.1 \%$ \\
\hline & Higher secondary & $5,072(16.9)$ & $31.7 \%$ \\
\hline & Graduate & $20,822(69.3)$ & $36.2 \%$ \\
\hline \multirow[t]{3}{*}{ Living situation } & Lives alone & $6,494(21.6)$ & $21.3 \%$ \\
\hline & Lives with others & $23,536(78.4)$ & $78.7 \%$ \\
\hline & Missing & 3 & \\
\hline \multirow[t]{4}{*}{ Marital status } & Cohabiting with partner/spouse & $19,272(64.2)$ & $62.2 \%$ \\
\hline & Living apart from partner/spouse & $1,648(5.5)$ & $5.9 \%$ \\
\hline & Divorced/widowed & $4,567(15.2)$ & $14.6 \%$ \\
\hline & Single, never married & $4,546(15.1)$ & $17.3 \%$ \\
\hline \multirow[t]{2}{*}{ Employment } & In employment & $17,323(57.7)$ & $50.2 \%$ \\
\hline & Retired / not working & $12,710(42.3)$ & $49.8 \%$ \\
\hline \multirow[t]{3}{*}{ Household income } & $<£ 30,000$ & $10,937(40.5)$ & $50.6 \%$ \\
\hline & $\geq £ 30,000$ & $16,093(59.5)$ & $49.4 \%$ \\
\hline & Prefer not to say & 3,003 & \\
\hline \multirow{4}{*}{$\begin{array}{l}\text { 'Keyworker' status: } \\
\text { employed in the } \\
\text { following jobs: }\end{array}$} & $\begin{array}{l}\text { Health, social care or relevant } \\
\text { related support worker }\end{array}$ & $2,807(9.4)$ & $6.9 \%$ \\
\hline & $\begin{array}{l}\text { Teacher or childcare worker still } \\
\text { travelling to work }\end{array}$ & $965(3.2)$ & $2.1 \%$ \\
\hline & Other 'keyworker' & $2,368(7.9)$ & $9.2 \%$ \\
\hline & None of these & $23,893(79.6)$ & $81.7 \%$ \\
\hline Self-described carer & & $4,618(15.4)$ & $14.0 \%$ \\
\hline \multirow{3}{*}{$\begin{array}{l}\text { Usual face-to-face } \\
\text { contact with others } \\
\text { socially }\end{array}$} & Less than once weekly & $8,497(28.4)$ & $30.9 \%$ \\
\hline & Once or twice per week & $10,183(34.0)$ & $33.5 \%$ \\
\hline & Three or more per week & $11,295(37.7)$ & $35.5 \%$ \\
\hline \multicolumn{2}{|c|}{ Having a long-term health condition } & $12,786(42.6)$ & $46.8 \%$ \\
\hline \multirow{5}{*}{$\begin{array}{l}\text { Personality } \\
\text { characteristics mean } \\
\text { score (sd, range) } \\
\text { (missing = 123) }\end{array}$} & Neuroticism & $11.1(4.3,3-21) *$ & $11.0(10.9,11.1)^{*}$ \\
\hline & Extroversion & $12.8(4.3,3-21)^{*}$ & $12.6(12.5,12.7) *$ \\
\hline & Openness to experience & $15.4(3.3,3-21) *$ & $14.9(14.9,15.0) *$ \\
\hline & Agreeableness & $15.5(3.0,3-21)^{*}$ & $15.4(15.3,15.4) *$ \\
\hline & Conscientiousness & $16.0(2.9,3-21) *$ & $15.8(15.7,15.8) *$ \\
\hline \multirow{2}{*}{$\begin{array}{l}\text { Interpersonal } \\
\text { reactivity index mean } \\
\text { score (sd, range) }\end{array}$} & Empathic concern & $3.97(0.66,1-5) *$ & $3.86(3.85,3.88) *$ \\
\hline & Perspective taking & $3.67(0.69,1-5) *$ & $3.57(3.56,3.59) *$ \\
\hline
\end{tabular}

Notes: $\mathbf{s d}$ = standard deviation. Weighted data matched to the UK proportions of gender, age, ethnicity, education and country of living from the Office for National Statistics (ONS, 2018) 
Figure 2. Mean empathic concern and perspective taking scores by age and gender






\begin{tabular}{|c|c|c|c|c|c|}
\hline & & \multicolumn{2}{|c|}{$\begin{array}{l}\text { Unweighted univariable } \\
\text { Complete cases }\end{array}$} & \multicolumn{2}{|l|}{ Weighted multivariable } \\
\hline & & Coefficient & $P$ value & Coefficient & $P$ value \\
\hline \multirow[t]{7}{*}{ Age (years) } & $18-25$ & Reference & \multirow[t]{7}{*}{$<0.001$} & Reference & \multirow[t]{7}{*}{0.04} \\
\hline & $25-34$ & $-0.07(-0.18,0.03)$ & & $-0.06(-0.15,0.03)$ & \\
\hline & $35-44$ & $-0.12(-0.23,-0.02)$ & & $-0.06(-0.15,0.03)$ & \\
\hline & $45-54$ & $-0.10(-0.21,-0.00)$ & & $-0.02(-0.10,0.07)$ & \\
\hline & $55-64$ & $-0.14(-0.24,-0.04)$ & & $-0.01(-0.10,0.08)$ & \\
\hline & $65-74$ & $-0.16(-0.26,-0.06)$ & & $0.02(-0.07,0.11)$ & \\
\hline & $\geq 75$ & $-0.21(-0.32,-0.09)$ & & $0.01(-0.10,0.11)$ & \\
\hline \multirow[t]{2}{*}{ Gender } & Male & Reference & \multirow[t]{2}{*}{$<0.001$} & Reference & \multirow[t]{2}{*}{$<0.001$} \\
\hline & Female & $0.37(0.34,0.39)$ & & $0.23(0.21,0.26)$ & \\
\hline \multirow[t]{2}{*}{ Ethnicity } & White & Reference & \multirow[t]{2}{*}{0.18} & Reference & \multirow[t]{2}{*}{0.01} \\
\hline & Other & $0.05(-0.02,0.12)$ & & $0.08(0.02,0.14)$ & \\
\hline \multirow{3}{*}{$\begin{array}{l}\text { Educational } \\
\text { level }\end{array}$} & Lower secondary (ref) & Reference & \multirow[t]{3}{*}{$<0.001$} & Reference & \multirow[t]{3}{*}{0.02} \\
\hline & Higher secondary & $0.04(0.00,0.08)$ & & $0.00(-0.03,0.04)$ & \\
\hline & Graduate & $0.09(0.06,0.12)$ & & $0.04(0.00,0.07)$ & \\
\hline \multirow[t]{2}{*}{ Living status } & Alone (ref) & Reference & \multirow[t]{2}{*}{0.20} & Reference & \multirow[t]{2}{*}{0.92} \\
\hline & With others & $0.02(-0.01,0.05)$ & & $0.00(-0.04,0.04)$ & \\
\hline \multirow{4}{*}{$\begin{array}{l}\text { Marital } \\
\text { status }\end{array}$} & Single (ref) & Reference & \multirow[t]{4}{*}{0.004} & Reference & \multirow[t]{4}{*}{0.14} \\
\hline & Divorced/widowed & $0.09(0.04,0.14)$ & & $0.02(-0.02,0.07)$ & \\
\hline & Non cohabiting partner & $0.06(-0.01,0.14)$ & & $0.04(-0.02,0.10)$ & \\
\hline & Married/cohabiting & $0.03(-0.01,0.07)$ & & $0.05(0.01,0.10)$ & \\
\hline \multirow[t]{2}{*}{ Employment } & Not working (ref) & Reference & \multirow[t]{2}{*}{0.11} & Reference & \multirow[t]{2}{*}{0.86} \\
\hline & Working & $0.02(-0.01,0.05)$ & & $0.00(-0.03,0.03)$ & \\
\hline \multirow{2}{*}{$\begin{array}{l}\text { Household } \\
\text { income } \\
\end{array}$} & $<\mathrm{f} 30,000$ (ref) & Reference & \multirow[t]{2}{*}{0.54} & Reference & 0.66 \\
\hline & $\geq £ 30,000$ & $-0.01(-0.04,0.02)$ & & $-0.01(-0.03,0.02)$ & \\
\hline 'Keyworker' & None of these (ref) & Reference & $<0.001$ & Reference & $<0.001$ \\
\hline status & Health/social-care & $0.17(0.12,0.22)$ & & $0.11(0.06,0.15)$ & \\
\hline & Teacher/childcare & $0.22(0.15,0.29)$ & & $0.06(0.00,0.11)$ & \\
\hline & Other 'keyworker' & $-0.08(-0.13,-0.03)$ & & $-0.01(-0.05,0.04)$ & \\
\hline Carer status & Not carer (ref) & Reference & $<0.001$ & Reference & 0.57 \\
\hline & carer & $0.09(0.05,0.12)$ & & $0.01(-0.02,0.04)$ & \\
\hline Face-to-face & $<1$ time per week (ref) & Reference & $<0.001$ & Reference & 0.10 \\
\hline social & 1-2 times per week & $0.07(0.03,0.10)$ & & $0.02(-0.01,0.04)$ & \\
\hline contact & $3+$ times per week & $0.13(0.09,0.16)$ & & $0.03(0.07,0.00)$ & \\
\hline Long-term & No (ref) & Reference & 0.88 & Reference & 0.12 \\
\hline condition & Yes & $0.00(-0.03,0.03)$ & & $0.02(-0.01,0.04)$ & \\
\hline Personality & Neuroticism & $0.09(0.07,0.10)$ & $<0.001$ & $0.11(0.10,0.12)$ & $<0.001$ \\
\hline mean score & Extroversion & $0.11(0.10,0.12)$ & $<0.001$ & $0.06(0.05,0.07)$ & $<0.001$ \\
\hline $\begin{array}{l}\text { (per one } \\
\text { standard }\end{array}$ & $\begin{array}{l}\text { Openness to } \\
\text { experience }\end{array}$ & $0.14(0.13,0.16)$ & $<0.001$ & $0.11(0.10,0.13)$ & $<0.001$ \\
\hline deviation & Agreeableness & $0.27(0.25,0.28)$ & $<0.001$ & $0.24(0.23,0.25)$ & $<0.001$ \\
\hline higher) & Conscientiousness & $0.10(0.08,0.11)$ & $<0.001$ & $-0.01(-0.02,0.01)$ & 0.48 \\
\hline
\end{tabular}

Notes: Linear regression models weighted to the UK proportions of gender, age, ethnicity, education and country of living obtained from the Office for National Statistics (ONS, 2018). Multivariable models are mutually adjusted for included variables. Coefficients indicate estimated difference in interpersonal reactivity index empathic concern score according to respondent characteristic. 


\begin{tabular}{|c|c|c|c|c|c|}
\hline & & \multicolumn{2}{|c|}{ Weighted univariable } & \multicolumn{2}{|c|}{ Weighted multivariable } \\
\hline & & Coefficient & $P$ value & Coefficient & $\mathrm{P}$ value \\
\hline \multirow[t]{7}{*}{ Age (years) } & $18-25$ & Reference & \multirow[t]{7}{*}{$<0.001$} & Reference & \multirow[t]{7}{*}{$<0.001$} \\
\hline & $25-34$ & $-0.01(-0.09,0.12)$ & & $-0.05(-0.14,0.04)$ & \\
\hline & $35-44$ & $-0.00(-0.11,0.10)$ & & $-0.04(-0.13,0.04)$ & \\
\hline & $45-54$ & $-0.05(-0.15,0.05)$ & & $-0.09(-0.18,-0.01)$ & \\
\hline & $55-64$ & $-0.11(-0.21,-0.01)$ & & $-0.13(-0.22,-0.04)$ & \\
\hline & $65-74$ & $-0.12(-0.22,-0.02)$ & & $-0.13(-0.22,-0.04)$ & \\
\hline & $\geq 75$ & $-0.24(-0.36,-0.12)$ & & $-0.23(-0.34,-0.13)$ & \\
\hline \multirow[t]{2}{*}{ Gender } & Male & Reference & \multirow[t]{2}{*}{$<0.001$} & Reference & \multirow[t]{2}{*}{$<0.001$} \\
\hline & Female & $0.27(0.24,0.29)$ & & $0.18(0.16,0.21)$ & \\
\hline \multirow[t]{2}{*}{ Ethnicity } & White & Reference & \multirow[t]{2}{*}{0.68} & Reference & \multirow[t]{2}{*}{0.99} \\
\hline & Other & $0.02(-0.06,0.09)$ & & $-0.00(-0.06,0.06)$ & \\
\hline \multirow{3}{*}{$\begin{array}{l}\text { Educational } \\
\text { level }\end{array}$} & Lower secondary (ref) & Reference & \multirow[t]{3}{*}{$<0.001$} & Reference & \multirow[t]{3}{*}{$<0.001$} \\
\hline & Higher secondary & $0.12(0.08,0.16)$ & & $0.06(0.02,0.10)$ & \\
\hline & Graduate & $0.18(0.15,0.22)$ & & $0.09(0.06,0.12)$ & \\
\hline \multirow[t]{2}{*}{ Living status } & Alone (ref) & Reference & \multirow[t]{2}{*}{0.56} & Reference & \multirow[t]{2}{*}{0.57} \\
\hline & With others & $0.01(-0.02,0.04)$ & & $-0.01(-0.06,0.03)$ & \\
\hline \multirow{4}{*}{$\begin{array}{l}\text { Marital } \\
\text { status }\end{array}$} & Single (ref) & Reference & \multirow[t]{4}{*}{0.02} & Reference & \multirow[t]{4}{*}{0.39} \\
\hline & Divorced/widowed & $0.06(0.01,0.11)$ & & $0.04(-0.01,0.09)$ & \\
\hline & Non cohabiting partner & $0.04(-0.05,0.12)$ & & $0.03(-0.04,0.10)$ & \\
\hline & Married/cohabiting & $-0.00(-0.04,0.04)$ & & $0.02(-0.02,0.07)$ & \\
\hline \multirow[t]{2}{*}{ Employment } & Not working (ref) & Reference & \multirow[t]{2}{*}{$<0.001$} & Reference & \multirow[t]{2}{*}{0.73} \\
\hline & Working & $0.08(0.05,0.11)$ & & $0.01(-0.03,0.04)$ & \\
\hline \multirow{2}{*}{$\begin{array}{l}\text { Household } \\
\text { income }\end{array}$} & $<£ 30,000$ (ref) & Reference & \multirow[t]{2}{*}{$<0.001$} & Reference & 0.25 \\
\hline & $\geq £ 30,000$ & $0.04(0.02,0.05)$ & & $0.02(-0.01,0.05)$ & \\
\hline 'Keyworker' & None of these (ref) & Reference & $<0.001$ & Reference & 0.07 \\
\hline status & Health/social-care & $0.17(0.13,0.21)$ & & $0.05(0.01,0.10)$ & \\
\hline & Teacher/childcare & $0.17(0.09,0.26)$ & & $-0.02(-0.09,0.06)$ & \\
\hline & Other 'keyworker' & $-0.01(-0.07,0.02)$ & & $0.01(-0.03,0.06)$ & \\
\hline Carer status & Not carer (ref) & Reference & $<0.001$ & Reference & 0.09 \\
\hline & carer & $0.08(0.05,0.12)$ & & $0.03(-0.00,0.06)$ & \\
\hline Face-to-face & $<1$ time per week (ref) & Reference & $<0.001$ & Reference & 0.90 \\
\hline social & 1-2 times per week & $0.06(0.02,0.09)$ & & $0.01(-0.02,0.04)$ & \\
\hline contact & $3+$ times per week & $0.09(0.05,0.12)$ & & $0.00(-0.03,0.03)$ & \\
\hline Long-term & No (ref) & Reference & $<0.001$ & Reference & 0.99 \\
\hline condition & Yes & $-0.07(-0.10,-0.04)$ & & $-0.00(-0.03,0.03)$ & \\
\hline Personality & Neuroticism & $-0.06(-0.08,-0.05)$ & $<0.001$ & $-0.08(-0.08,-0.06)$ & $<0.001$ \\
\hline mean score & Extroversion & $0.07(0.06,0.08)$ & $<0.001$ & $-0.01(-0.02,0.01)$ & 0.22 \\
\hline $\begin{array}{l}\text { (per one } \\
\text { standard }\end{array}$ & $\begin{array}{l}\text { Openness to } \\
\text { experience }\end{array}$ & $0.13(0.11,0.14)$ & $<0.001$ & $0.09(0.08,0.11)$ & $<0.001$ \\
\hline deviation & Agreeableness & $0.29(0.27,0.30)$ & $<0.001$ & $0.26(0.24,0.27)$ & $<0.001$ \\
\hline higher) & Conscientiousness & $0.12(0.11,0.14)$ & $<0.001$ & $0.01(-0.01,0.02)$ & 0.20 \\
\hline
\end{tabular}

Notes: Linear regression models weighted to the UK proportions of gender, age, ethnicity, education and country of living obtained from the Office for National Statistics (ONS, 2018). Multivariable models are mutually adjusted for included variables. Coefficients indicate estimated difference in interpersonal reactivity index perspective taking score according to respondent characteristic. 
Appendix 1 - Mean unweighted scores on empathic concern and perspective taking scales according to sociodemographic characteristics ( $n=25,169)$

\begin{tabular}{|c|c|c|c|c|c|}
\hline & & \multicolumn{2}{|c|}{ Empathic concern } & \multicolumn{2}{|c|}{ Perspective taking } \\
\hline & & Mean & sd & Mean & $\mathrm{sd}$ \\
\hline \multirow[t]{7}{*}{ Age (years) } & $18-25$ & 4.01 & 0.67 & 3.71 & 0.68 \\
\hline & $25-34$ & 4.00 & 0.65 & 3.70 & 0.65 \\
\hline & $35-44$ & 4.00 & 0.66 & 3.72 & 0.66 \\
\hline & $45-54$ & 4.02 & 0.68 & 3.71 & 0.69 \\
\hline & $55-64$ & 3.97 & 0.67 & 3.62 & 0.71 \\
\hline & $65-74$ & 3.91 & 0.65 & 3.62 & 0.69 \\
\hline & $\geq 75$ & 3.87 & 0.63 & 3.55 & 0.69 \\
\hline \multirow[t]{3}{*}{ Gender } & Male & 3.70 & 0.66 & 3.48 & 0.69 \\
\hline & Female & 4.06 & 0.64 & 3.74 & 0.68 \\
\hline & Other / prefer not to say & 3.95 & 0.64 & 3.49 & 0.64 \\
\hline \multirow[t]{2}{*}{ Ethnicity } & White & 3.97 & 0.66 & 3.68 & 0.69 \\
\hline & Other & 4.02 & 0.67 & 3.66 & 0.69 \\
\hline \multirow[t]{3}{*}{ Educational level } & Lower secondary & 3.90 & 0.69 & 3.54 & 0.73 \\
\hline & Higher secondary & 3.94 & 0.68 & 3.64 & 0.71 \\
\hline & Graduate & 3.99 & 0.65 & 3.71 & 0.67 \\
\hline \multirow[t]{2}{*}{ Living status } & Alone & 3.93 & 0.67 & 3.64 & 0.70 \\
\hline & With others & 3.98 & 0.66 & 3.68 & 0.69 \\
\hline \multirow[t]{4}{*}{ Marital status } & Single & 3.91 & 0.68 & 3.62 & 0.69 \\
\hline & Divorced/widowed & 4.00 & 0.67 & 3.71 & 0.71 \\
\hline & Non cohabiting partner & 3.99 & 0.67 & 3.70 & 0.66 \\
\hline & Married/cohabiting & 3.97 & 0.66 & 3.68 & 0.68 \\
\hline \multirow[t]{2}{*}{ Employment } & Not working & 3.94 & 0.66 & 3.63 & 0.71 \\
\hline & Working & 3.99 & 0.66 & 3.71 & 0.67 \\
\hline \multirow[t]{2}{*}{ Household income } & $<£ 30,000$ & 3.97 & 0.67 & 3.66 & 0.71 \\
\hline & $\geq £ 30,000$ & 3.97 & 0.65 & 3.69 & 0.67 \\
\hline \multirow[t]{4}{*}{ ‘Keyworker’ status } & None of these & 3.95 & 0.66 & 3.66 & 0.69 \\
\hline & Health/social-care & 4.11 & 0.64 & 3.80 & 0.67 \\
\hline & Teacher/childcare & 4.13 & 0.65 & 3.79 & 0.67 \\
\hline & Other 'keyworker' & 3.91 & 0.67 & 3.65 & 0.68 \\
\hline \multirow[t]{2}{*}{ Carer status } & Not carer & 3.95 & 0.66 & 3.66 & 0.69 \\
\hline & carer & 4.04 & 0.65 & 3.73 & 0.69 \\
\hline \multirow{3}{*}{$\begin{array}{l}\text { Face-to-face social } \\
\text { contact }\end{array}$} & $<1$ time per week & 3.90 & 0.69 & 3.62 & 0.70 \\
\hline & 1-2 times per week & 3.97 & 0.66 & 3.68 & 0.68 \\
\hline & $3+$ times per week & 4.02 & 0.64 & 3.71 & 0.69 \\
\hline \multirow{2}{*}{$\begin{array}{l}\text { Long-term } \\
\text { condition }\end{array}$} & No & 3.96 & 0.66 & 3.69 & 0.67 \\
\hline & Yes & 3.97 & 0.66 & 3.65 & 0.71 \\
\hline \multirow[t]{3}{*}{ Neuroticism $^{a}$} & Low & 3.90 & 0.67 & 3.74 & 0.68 \\
\hline & Medium & 3.95 & 0.65 & 3.67 & 0.67 \\
\hline & High & 4.07 & 0.65 & 3.60 & 0.70 \\
\hline \multirow[t]{3}{*}{ Extroversion $^{a}$} & Low & 3.86 & 0.69 & 3.61 & 0.69 \\
\hline & Medium & 3.98 & 0.64 & 3.68 & 0.67 \\
\hline & High & 4.10 & 0.63 & 3.75 & 0.69 \\
\hline \multirow{3}{*}{$\begin{array}{l}\text { Openness to } \\
\text { experience }^{\text {a }}\end{array}$} & Low & 3.82 & 0.67 & 3.56 & 0.69 \\
\hline & Medium & 3.98 & 0.63 & 3.69 & 0.66 \\
\hline & High & 4.14 & 0.64 & 3.81 & 0.69 \\
\hline \multirow[t]{3}{*}{ Agreeableness $^{a}$} & Low & 3.69 & 0.66 & 3.36 & 0.67 \\
\hline & Medium & 4.00 & 0.60 & 3.72 & 0.61 \\
\hline & High & 4.27 & 0.59 & 4.00 & 0.63 \\
\hline \multirow{3}{*}{$\begin{array}{l}\text { Conscientiousness } \\
\text { a }\end{array}$} & Low & 3.87 & 0.65 & 3.56 & 0.67 \\
\hline & Medium & 3.99 & 0.64 & 3.71 & 0.66 \\
\hline & High & 4.12 & 0.69 & 3.75 & 0.72 \\
\hline
\end{tabular}

Notes: $\mathbf{s d}=$ standard deviation; ${ }^{\mathrm{a}}$ categorised into tertiles based on distribution in this sample 
Appendix 2. Association of participant characteristics with empathic concern - unweighted univariable and multivariable associations $(n=25,169)$

\begin{tabular}{|c|c|c|c|c|c|}
\hline & & \multicolumn{2}{|c|}{$\begin{array}{l}\text { Unweighted univariable } \\
\text { Complete cases }\end{array}$} & \multicolumn{2}{|c|}{$\begin{array}{l}\text { Unweighted multivariable } \\
\text { Complete cases }\end{array}$} \\
\hline & & Coefficient & $P$ value & Coefficient & $P$ value \\
\hline \multirow[t]{7}{*}{ Age (years) } & $18-25$ & Reference & \multirow[t]{7}{*}{$<0.001$} & Reference & \multirow[t]{7}{*}{0.003} \\
\hline & $25-34$ & $-0.02(-0.10,0.05)$ & & $0.01(-0.06,0.07)$ & \\
\hline & $35-44$ & $-0.03(-0.10,0.04)$ & & $0.04(-0.03,0.10)$ & \\
\hline & $45-54$ & $-0.01(-0.08,0.05)$ & & $0.07(0.00,0.13)$ & \\
\hline & $55-64$ & $-0.06(-0.13,0.01)$ & & $0.04(-0.03,0.10)$ & \\
\hline & $65-74$ & $-0.12(-0.19,-0.05)$ & & $0.02(-0.04,0.09)$ & \\
\hline & $\geq 75$ & $-0.15(-0.22,-0.07)$ & & $0.03(-0.04,0.10)$ & \\
\hline \multirow[t]{2}{*}{ Gender } & Male & Reference & \multirow[t]{2}{*}{$<0.001$} & Reference & \multirow[t]{2}{*}{$<0.001$} \\
\hline & Female & $0.36(0.34,0.38)$ & & $0.22(0.20,0.24)$ & \\
\hline \multirow[t]{2}{*}{ Ethnicity } & White & Reference & \multirow[t]{2}{*}{0.02} & Reference & \multirow[t]{2}{*}{0.001} \\
\hline & Other & $0.05(0.01,0.10)$ & & $0.06(0.02,0.10)$ & \\
\hline \multirow{3}{*}{$\begin{array}{l}\text { Educational } \\
\text { level }\end{array}$} & Lower secondary & Reference & \multirow[t]{3}{*}{$<0.001$} & Reference & \multirow[t]{3}{*}{0.001} \\
\hline & Higher secondary & $0.04(0.01,0.07)$ & & $0.00(-0.02,0.03)$ & \\
\hline & Graduate & $0.08(0.06,0.11)$ & & $0.03(0.01,0.06)$ & \\
\hline \multirow[t]{2}{*}{ Living } & Alone (ref) & Reference & \multirow[t]{2}{*}{$<0.001$} & Reference & \multirow[t]{2}{*}{0.02} \\
\hline & With others & $0.06(0.04,0.08)$ & & $0.03(0.01,0.06)$ & \\
\hline \multirow{4}{*}{$\begin{array}{l}\text { Marital } \\
\text { status }\end{array}$} & Single (ref) & Reference & \multirow[t]{4}{*}{$<0.001$} & Reference & \multirow[t]{4}{*}{0.10} \\
\hline & Divorced/widowed & $0.09(0.06,0.12)$ & & $0.03(0.00,0.06)$ & \\
\hline & Non cohabiting partner & $0.08(0.04,0.12)$ & & $0.01(-0.02,0.05)$ & \\
\hline & Married/cohabiting & $0.06(0.04,0.09)$ & & $0.03(0.00,0.06)$ & \\
\hline \multirow[t]{2}{*}{ Employment } & Not working (ref) & Reference & \multirow[t]{2}{*}{$<0.001$} & Reference & \multirow[t]{2}{*}{0.21} \\
\hline & Working & $0.05(0.03,0.07)$ & & $-0.01(-0.03,0.01)$ & \\
\hline \multirow{2}{*}{$\begin{array}{l}\text { Household } \\
\text { income }\end{array}$} & $<£ 30,000$ (ref) & Reference & \multirow[t]{2}{*}{0.51} & Reference & 0.98 \\
\hline & $\geq £ 30,000$ & $0.01(-0.01,-0.02)$ & & $-0.00(-0.02,0.02)$ & \\
\hline 'Keyworker' & None of these (ref) & Reference & $<0.001$ & Reference & $<0.001$ \\
\hline status & Health/social-care & $0.16(0.13,0.19)$ & & $0.10(0.08,0.13)$ & \\
\hline & Teacher/childcare & $0.18(0.14,0.23)$ & & $0.06(0.02,0.10)$ & \\
\hline & Other 'keyworker' & $-0.05(-0.08,-0.02)$ & & $-0.01(-0.04,0.01)$ & \\
\hline Carer status & Not carer (ref) & Reference & $<0.001$ & Reference & 0.05 \\
\hline & carer & $0.09(0.07,0.12)$ & & $0.02(0.00,0.04)$ & \\
\hline Face-to-face & $<1$ time per week (ref) & Reference & $<0.001$ & Reference & $<0.001$ \\
\hline social & 1-2 times per week & $0.08(0.06,0.10)$ & & $0.03(0.01,0.05)$ & \\
\hline contact & $3+$ times per week & $0.12(0.09,0.14)$ & & $0.03(0.01,0.05)$ & \\
\hline Long-term & No (ref) & Reference & 0.01 & Reference & $<0.001$ \\
\hline condition & Yes & $0.02(0.01,0.04)$ & & $0.03(0.02,0.05)$ & \\
\hline Personality & Neuroticism & $0.07(0.07,0.08)$ & $<0.001$ & $0.10(0.10,0.11)$ & $<0.001$ \\
\hline mean score & Extroversion & $0.11(0.10,0.12)$ & $<0.001$ & $0.06(0.05,0.07)$ & $<0.001$ \\
\hline $\begin{array}{l}\text { (per one } \\
\text { standard }\end{array}$ & $\begin{array}{l}\text { Openness to } \\
\text { experience }\end{array}$ & $0.14(0.13,0.15)$ & $<0.001$ & $0.11(0.11,0.12)$ & $<0.001$ \\
\hline deviation & Agreeableness & $0.26(0.25,0.27)$ & $<0.001$ & $0.24(0.23,0.24)$ & $<0.001$ \\
\hline higher) & Conscientiousness & $0.09(0.09,0.10)$ & $<0.001$ & $0.00(-0.01,0.01)$ & 0.50 \\
\hline
\end{tabular}

Notes: Linear regression models. Multivariable models are mutually adjusted for included variables. Coefficients indicate estimated difference in Interpersonal reactivity index empathic concern score according to respondent characteristic. 


\begin{tabular}{|c|c|c|c|c|c|}
\hline & & Empathic concern & & Perspective taking & \\
\hline & & Coefficient & $P$ value & Coefficient & $P$ value \\
\hline \multirow[t]{7}{*}{ Age (years) } & $18-25$ & Reference & \multirow[t]{7}{*}{0.13} & Reference & \multirow[t]{7}{*}{$<0.001$} \\
\hline & $25-34$ & $0.00(-0.08,0.08)$ & & $-0.02(-0.11,0.07)$ & \\
\hline & $35-44$ & $0.01(-0.08,0.09)$ & & $-0.01(-0.10,0.08)$ & \\
\hline & $45-54$ & $0.04(-0.04,0.12)$ & & $-0.06(-0.15,-0.03)$ & \\
\hline & $55-64$ & $0.05(-0.03,0.13)$ & & $-0.09(-0.18,-0.00)$ & \\
\hline & $65-74$ & $0.06(-0.02,0.14)$ & & $-0.09(-0.19,-0.00)$ & \\
\hline & $\geq 75$ & $0.04(-0.05,0.13)$ & & $-0.20(-0.30,-0.10)$ & \\
\hline \multirow[t]{3}{*}{ Gender } & Male & Reference & \multirow[t]{3}{*}{$<0.001$} & Reference & \multirow[t]{3}{*}{$<0.001$} \\
\hline & Female & $0.22(0.20,0.25)$ & & $0.18(0.16,0.21)$ & \\
\hline & Other/prefer not to say & $0.26(0.11,0.41)$ & & $0.12(-0.01,0.25)$ & \\
\hline \multirow[t]{2}{*}{ Ethnicity } & White & Reference & \multirow[t]{2}{*}{0.004} & Reference & \multirow[t]{2}{*}{0.81} \\
\hline & Other & $0.08(0.03,0.14)$ & & $0.01(-0.05,0.07)$ & \\
\hline \multirow{3}{*}{$\begin{array}{l}\text { Educational } \\
\text { level }\end{array}$} & Lower secondary & Reference & \multirow[t]{3}{*}{0.005} & Reference & \multirow[t]{3}{*}{$<0.001$} \\
\hline & Higher secondary & $0.01(-0.02,0.04)$ & & $0.06(0.03,0.09)$ & \\
\hline & Graduate & $0.04(0.01,0.07)$ & & $0.09(0.06,0.12)$ & \\
\hline \multirow[t]{2}{*}{ Living } & Alone (ref) & Reference & \multirow[t]{2}{*}{0.84} & Reference & \multirow[t]{2}{*}{0.63} \\
\hline & With others & $0.00(-0.04,0.04)$ & & $-0.01(-0.05,0.03)$ & \\
\hline \multirow{4}{*}{$\begin{array}{l}\text { Marital } \\
\text { status }\end{array}$} & Single (ref) & Reference & \multirow[t]{4}{*}{0.08} & Reference & \multirow[t]{4}{*}{0.30} \\
\hline & Divorced/widowed & $0.04(-0.00,0.08)$ & & $0.04(-0.00,0.08)$ & \\
\hline & Non cohabiting partner & $0.04(-0.01,0.10)$ & & $0.04(-0.02,0.10)$ & \\
\hline & Married/cohabiting & $0.05(0.01,0.09)$ & & $0.02(-0.01,0.08)$ & \\
\hline \multirow[t]{2}{*}{ Employment } & Not working (ref) & Reference & \multirow[t]{2}{*}{0.92} & Reference & \multirow[t]{2}{*}{0.67} \\
\hline & Working & $-0.00(-0.03,0.03)$ & & $0.01(-0.02,0.04)$ & \\
\hline \multirow{2}{*}{$\begin{array}{l}\text { Household } \\
\text { income }\end{array}$} & $<£ 30,000$ (ref) & Reference & \multirow[t]{2}{*}{0.78} & Reference & \multirow[t]{2}{*}{0.35} \\
\hline & $\geq £ 30,000$ & $-0.00(-0.03,0.02)$ & & $0.02(-0.01,0.04)$ & \\
\hline \multirow{4}{*}{$\begin{array}{l}\text { 'Keyworker' } \\
\text { status }\end{array}$} & None of these (ref) & Reference & $<0.001$ & Reference & 0.02 \\
\hline & Health/social-care & $0.11(0.06,0.15)$ & & $0.05(0.02,0.10)$ & \\
\hline & Teacher/childcare & $0.06(0.00,0.11)$ & & $-0.03(-0.10,0.03)$ & \\
\hline & Other 'keyworker' & $-0.01(-0.05,0.04)$ & & $0.02(-0.03,0.06)$ & \\
\hline Carer status & Not carer (ref) & Reference & 0.82 & Reference & 0.17 \\
\hline & carer & $0.00(-0.03,0.03)$ & & $0.02(-0.00,0.05)$ & \\
\hline Face-to-face & $<1$ time per week (ref) & Reference & 0.02 & Reference & 0.52 \\
\hline social & 1-2 times per week & $0.03(-0.00,0.05)$ & & $0.02(-0.01,0.05)$ & \\
\hline contact & $3+$ times per week & $0.04(0.01,0.07)$ & & $0.01(-0.02,0.04)$ & \\
\hline Long-term & No (ref) & Reference & 0.26 & Reference & 0.79 \\
\hline condition & Yes & $0.01(-0.01,0.04)$ & & $-0.00(-0.03,0.02)$ & \\
\hline Personality & Neuroticism & $0.11(0.10,0.12)$ & $<0.001$ & $-0.07(-0.08,-0.05)$ & $<0.001$ \\
\hline mean score & Extroversion & $0.06(0.05,0.07)$ & $<0.001$ & $-0.01(-0.02,0.01)$ & 0.39 \\
\hline $\begin{array}{l}\text { (per one } \\
\text { standard }\end{array}$ & $\begin{array}{l}\text { Openness to } \\
\text { experience }\end{array}$ & $0.11(0.10,0.12)$ & $<0.001$ & $0.09(0.07,0.10)$ & $<0.001$ \\
\hline deviation & Agreeableness & $0.24(0.23,0.26)$ & $<0.001$ & $0.26(0.24,0.27)$ & $<0.001$ \\
\hline higher) & Conscientiousness & $0.00(-0.01,0.01)$ & 0.96 & $0.01(-0.00,0.02)$ & 0.16 \\
\hline
\end{tabular}

Notes: Linear regression models, mutually adjusted for included variables, and weighted to the UK proportions of gender, age, ethnicity, education and country of living obtained from the Office for National Statistics. Coefficients indicate estimated difference in Interpersonal reactivity index empathic concern or perspective taking score according to respondent characteristic. 


\begin{tabular}{|c|c|c|c|c|c|}
\hline & & \multicolumn{2}{|c|}{ Unweighted univariable } & \multicolumn{2}{|c|}{ Unweighted multivariable } \\
\hline & & Coefficient & $P$ value & Coefficient & $P$ value \\
\hline \multirow[t]{7}{*}{ Age (years) } & $18-25$ & Reference & \multirow[t]{7}{*}{$<0.001$} & Reference & \multirow[t]{7}{*}{$<0.001$} \\
\hline & $25-34$ & $-0.02(-0.10,0.05)$ & & $-0.07(-0.14,-0.00)$ & \\
\hline & $35-44$ & $-0.00(-0.07,0.07)$ & & $-0.05(-0.11,0.02)$ & \\
\hline & $45-54$ & $-0.02(-0.09,0.05)$ & & $-0.08(-0.14,-0.01)$ & \\
\hline & $55-64$ & $-0.05(-0.12,0.02)$ & & $-0.11(-0.17,-0.04)$ & \\
\hline & $65-74$ & $-0.11(-0.18,-0.04)$ & & $-0.14(-0.21,-0.07)$ & \\
\hline & $\geq 75$ & $-0.18(-0.26,-0.10)$ & & $-0.19(-0.26,-0.12)$ & \\
\hline \multirow[t]{2}{*}{ Gender } & Male & Reference & \multirow[t]{2}{*}{$<0.001$} & Reference & \multirow[t]{2}{*}{$<0.001$} \\
\hline & Female & $0.26(0.24,0.28)$ & & $0.18(0.16,0.20)$ & \\
\hline \multirow[t]{2}{*}{ Ethnicity } & White & Reference & \multirow[t]{2}{*}{0.51} & Reference & \multirow[t]{2}{*}{0.21} \\
\hline & Other & $-0.01(-0.06,0.03)$ & & $-0.03(-0.06,0.01)$ & \\
\hline \multirow{3}{*}{$\begin{array}{l}\text { Educational } \\
\text { level }\end{array}$} & Lower secondary & Reference & \multirow[t]{3}{*}{$<0.001$} & Reference & \multirow[t]{3}{*}{$<0.001$} \\
\hline & Higher secondary & $0.11(0.08,0.14)$ & & $0.06(0.03,0.09)$ & \\
\hline & Graduate & $0.17(0.15,0.20)$ & & $0.11(0.08,0.13)$ & \\
\hline \multirow[t]{2}{*}{ Living } & Alone (ref) & Reference & \multirow[t]{2}{*}{$<0.001$} & Reference & \multirow[t]{2}{*}{0.14} \\
\hline & With others & $0.04(0.02,0.06)$ & & $0.02(-0.01,0.05)$ & \\
\hline \multirow{4}{*}{$\begin{array}{l}\text { Marital } \\
\text { status }\end{array}$} & Single (ref) & Reference & \multirow[t]{4}{*}{$<0.001$} & Reference & \multirow[t]{4}{*}{0.001} \\
\hline & Divorced/widowed & $0.09(0.06,0.13)$ & & $0.06(0.03,0.09)$ & \\
\hline & Non cohabiting partner & $0.08(0.04,0.12)$ & & $0.03(-0.00,0.07)$ & \\
\hline & Married/cohabiting & $0.05(0.02,0.07)$ & & $0.02(-0.01,0.05)$ & \\
\hline \multirow[t]{2}{*}{ Employment } & Not working (ref) & Reference & \multirow[t]{2}{*}{$<0.001$} & Reference & \multirow[t]{2}{*}{0.57} \\
\hline & Working & $0.08(0.06,0.09)$ & & $0.01(-0.01,0.03)$ & \\
\hline \multirow{2}{*}{$\begin{array}{l}\text { Household } \\
\text { income }\end{array}$} & $<£ 30,000$ (ref) & Reference & \multirow[t]{2}{*}{$<0.001$} & Reference & 0.76 \\
\hline & $\geq £ 30,000$ & $0.04(0.02,0.05)$ & & $0.00(-0.02,0.02)$ & \\
\hline 'Keyworker' & None of these (ref) & Reference & $<0.001$ & Reference & 0.01 \\
\hline status & Health/social-care & $0.14(0.12,0.17)$ & & $0.04(0.02,0.07)$ & \\
\hline & Teacher/childcare & $0.14(0.10,0.19)$ & & $0.01(-0.04,0.05)$ & \\
\hline & Other 'keyworker' & $-0.01(-0.05,0.02)$ & & $-0.00(-0.03,0.03)$ & \\
\hline Carer status & Not carer (ref) & Reference & $<0.001$ & Reference & 0.14 \\
\hline & carer & $0.07(0.05,0.09)$ & & $0.02(-0.01,0.04)$ & \\
\hline Face-to-face & $<1$ time per week (ref) & Reference & $<0.001$ & Reference & 0.29 \\
\hline social & 1-2 times per week & $0.06(0.04,0.08)$ & & $0.01(-0.01,0.03)$ & \\
\hline contact & $3+$ times per week & $0.09(0.07,0.11)$ & & $0.01(-0.01,0.03)$ & \\
\hline Long-term & No (ref) & Reference & $<0.001$ & Reference & 0.68 \\
\hline condition & Yes & $-0.04(-0.06,-0.02)$ & & $0.00(-0.01,0.02)$ & \\
\hline Personality & Neuroticism & $-0.07(-0.08,-0.06)$ & $<0.001$ & $-0.06(-0.07,-0.05)$ & $<0.001$ \\
\hline mean score & Extroversion & $0.06(0.05,0.07)$ & $<0.001$ & $-0.02(-0.02,-0.01)$ & $<0.001$ \\
\hline $\begin{array}{l}\text { (per one } \\
\text { standard }\end{array}$ & $\begin{array}{l}\text { Openness to } \\
\text { experience }\end{array}$ & $0.12(0.11,0.13)$ & $<0.001$ & $0.09(0.08,0.10)$ & $<0.001$ \\
\hline deviation & Agreeableness & $0.29(0.28,0.30)$ & $<0.001$ & $0.27(0.26,0.28)$ & $<0.001$ \\
\hline higher) & Conscientiousness & $0.12(0.11,0.13)$ & $<0.001$ & $0.01(0.00,0.02)$ & 0.009 \\
\hline
\end{tabular}

Notes: Linear regression models. Multivariable models are mutually adjusted for included variables. Coefficients indicate estimated difference in Interpersonal reactivity index perspective taking score according to respondent characteristic. 